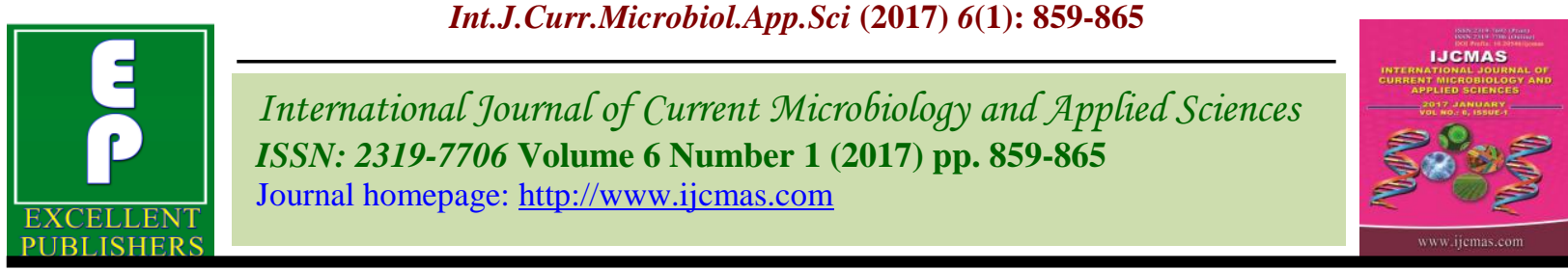

Original Research Article

http://dx.doi.org/10.20546/ijcmas.2017.601.101

\title{
Anti Biofilm and Anti Plasmid Activites of Syzygium aromaticum and Kaempheria galanga against Pseudomonas aeruginosa
}

\author{
Neelima Christopher ${ }^{1}$, Rajesh Ramachandran ${ }^{2 *}$ and Khaleel Ahamed Thaha ${ }^{3}$ \\ ${ }^{1}$ Student, SBST, VIT University, Vellore, India \\ ${ }^{2}$ Director, Biogenix Research Center, Trivandrum, India \\ ${ }^{3}$ Senior Resident, Dept. of Conservative Dentistry \& Endodontics, Govt. \\ Dental College, Trivandrum, India \\ *Corresponding author:
}

\section{A B S T R A C T}

Objective of the research was to validate the potential of Syzygium aromaticum and Kaempheria galanga against biofilm formation and plasmid borne drug resistance

\begin{tabular}{|l|}
\hline Key w or d s \\
Kaempheria \\
galangal, \\
Anti Biofilm and \\
$\begin{array}{l}\text { Anti Plasmid } \\
\text { Pseudomonas } \\
\text { aeruginosa }\end{array}$ \\
\hline Article Info \\
\hline Accepted: \\
28 December 2016 \\
Available Online: \\
10 January 2017 \\
\hline \hline
\end{tabular}
exhibited by Pseudomonas spp. Antimicrobial property of S.aromaticum and $K$.galanga on P.aeruginosa culture was assessed using the agar well diffusion method. Crystal violet assay was employed to determine the percentage inhibition of P.aeruginosa biofilm by the extracts following generation of biofilm on multiwell plates. The decrease in Pseudomonas viability in an established biofilm after treatment was determined by standard MTT reduction assay. Fluorescent microscopy following staining with Ethidium bromide and Acridine orange was done to distinguish the dead and live cells in the biofilm. Finally, antiplasmid activity was established by agarose gel electrophoresis. The extracts were found to have potent antibacterial activity and inhibited biofilm attachment to polymeric surfaces. They further exhibited a significant decrease in biofilm bacterial cell viability when determined by MTT assay and fluorescent staining. $S$ aromaticum effectively removed plasmids from Pseudomonas spp which can be due to their potential curing efficiency. The results obtained from the study validate the antibacterial and anti plasmid potential of extracts from Syzygium aromaticum and Kaempheria galanga against P.aeruginosa biofilm. The combination may be recommended as a potential drug to prevent biofilm formation and plasmid borne drug resistance.

\section{Introduction}

Biofilms are defined as a structured complex community of microorganisms that adhere to solid substrates and are embedded in an extracellular polymeric substance produced by the inhabitants (Strosmeyer and Maric, 2007). Biofilms in general can contribute to deleterious environmental effects and those formed by pathogenic microorganisms, in particular, can render massive outbreaks of food and water contamination so also fatal infections like cystic fibrosis (Horstkotte et al., 1998), prosthesis centered infection, infections associated with valves, catheter and other 
medical devices. In addition, the complexity of structure, increased resistance to biocides and anti microbials and perdurable nature leaves huge socio economic significance (Neils et al., 2010).

Pseudomonas aeruginosa, one of the most common treatment resistant pathogen, are gram negative opportunists which establishes as a highly organised biofilm. They cause a number of infections like pneumonia, septic shock, urinary / gastro intestinal tract infections Biofilm of Pseudomonas spp gains attention since the adaptive and other genetic changes of this organism inside biofilm make them resistant to almost all known antibiotics and antimicrobial agents causing Pseudomonas infections most life threatening and uncontrollable (Sharma et al., 2014).

Since most of the disinfectants and cleansing agents are proven to be less effective against biofilms (Cha et al., 1998), antibiotic therapy remains the last resort but the regular usage of which can lead to resistance (Kai et al., 2001). Considering all these, the antibiofilm potential of natural materials which are proven remedies to various diseases need to be evaluated. Phytochemicals or secondary metabolites, the bioactive principle of plants are established biofilm removing agents (Chirangini et al., 2005, Fu et al., 2007). S.aromaticum and K.galanga are found in Asia and Africa and are valued for their rich medicinal and culinary attributes (Jia et al., 2011). Further, the antimicrobial,anti-carminative(Shyamala et al., 2003) and antioxidant properties of these are well demonstrated. In addition, K.galanga also possess vaso-relaxant, anti inflammatory and analgesic properties. The current study deals with the utilization of Clove (Syzygium aromaticum) and sand ginger (Kaempheria galanga) against the biofilms produced by Pseudomonas aeruginosa.

\section{Materials and Methods}

Buds of S.aromaticum and rhizomes of K.galanga were collected from Trivandrum, Kerala, India. Ethanolic extracts of the agents were prepared via cold extraction method, dried under pressure and used for further studies

\section{Determination of antimicrobial property}

The antimicrobial properties of extracts were determined by agar well diffusion method. P.aeruginosa culture was swabbed on Muller Hinton Agar plates. Wells were punched on each plate and different concentrations of the extracts $(25,50$ and $100 \mu \mathrm{g} / \mathrm{ml}$ ) were added to the wells. The plates were incubated at $37^{\circ} \mathrm{C}$ overnight and the antimicrobial activities were determined by studying the zone of inhibition in $\mathrm{mm}$.

Determination of percentage inhibition of P.aeruginosa biofilm by antimicrobial agents-Crystal violet assay (O'Toole 2011)

P. aeruginosa biofilm was established in 96 well plates (Nunc, USA) by incubating them for a week. On the day preceeding the experiment, the wells containing biofilm were treated with various volumes of sodium hypochlorite, S.aromaticum extract and K.galanga extract $(25,50,100$ and $200 \mu 1)$. After incubating for 24 hours,at $37^{\circ} \mathrm{C}$, the wells were washed with phosphate buffered saline (PBS) and stained with $1 \%$ crystal violet. The stained adhered cells were removed by using micropippeting method and dissolved in $300 \mu \mathrm{l}$ Di methyl sulphoxide (DMSO) after washing with PBS. The percentage inhibition was determined following reading the absorbance at 600nm (Agilent Cary 60, USA). 
Determination of bacterial cell viabilitty MTT reduction assay (Hengwei et al., 2010)

P.aeruginosa grown on 96 well plates was treated with various concentration of extracts of S.aromaticum and K.galanga $(25 \mu \mathrm{g} / \mathrm{ml}, 50 \mu \mathrm{g} / \mathrm{ml}, 100 \mu \mathrm{g} / \mathrm{ml}, 200 \mu \mathrm{g} / \mathrm{ml})$. These were incubated overnight at $37^{\circ} \mathrm{C}$. $200 \mu \mathrm{l}$ of the treated culture (also control) was subjected to treatment with $20 \mu 1$ MTT. This was subjected for centrifugation. The formazan crystals so developed were centrifuged again to obtain pellets, which were dissolved in $2 \mathrm{ml}$ of DMSO and the percentage of the cell viability was determined by reading the absorbance at550nm (Agilent Cary 60, USA)..

Fluorescent staining of Biofilms (Ribble $e t$ al., 2005)

P.aeruginosa grown in well plate was subjected to antimicrobial treatment. They were washed in PBS and stained with a mixture of ethidium bromide and acridine orange for 5-10 minutes. The excess stain was removed and the plates were washed with PBS. The multi well plates were viewed under fluorescent microscope to observe the biofilm. The combination of stains used help to distinguish the dead and live cells in the biofilm which are seen as red and green respectively.

\section{Antiplasmid activity}

P.aeruginosa in multiwell plates were treated with sodium hypochlorite, S.aromaticum and K.galanga extracts $(100 \mu \mathrm{g} / \mathrm{ml})$. Following which isolation of plasmid was carried out using Favor MiniPrep Plasmid isolation Kit (Jena Bioscience GmbH, Loebstedter Strasse, Jena, Germany). Once the pellets containing plasmids were obtained, they were washed and eluted with the respective buffers as per the manufacturers instruction. These samples were loaded on $1 \%$ agarose gel and the resolved bands were viewed under gel imager.

\section{Results and Discussion}

Determination of antimicrobial activityagar well diffusion method

Upon performing agar well diffusion method for studying the antimicrobial potential of S.aromaticum and K.galanga, it was found that S.aromaticum is having higher antimicrobial resistance when compared to that of the latter.At the highest concentration $(100 \mu \mathrm{g} / \mathrm{ml})$, it shows a zone of inhibition of $30+/-2 \mathrm{~mm}$ while $K$.galanga has only $16+/-2 \mathrm{~mm}$. The activity of S.aromaticum is comparable to the results obtained with standard Streptomycin.

\section{Crystal violet assay}

The rate of inhibition of P.aeruginosa biofilms was evaluated with crystal violet assay.It was found that with the increase in concentration of extracts a dose dependent decrease in biofilm formation was observed. As the concentration of S.aromaticum extracts increases, the percentage rate of inhibition is found to increase from $36.9 \pm 4.9$ to $68.4 \pm 0.05$.

Likewise, percentage inhibition of the biofilm increases from $56.4 \pm 0.6$ to $66.4 \pm 0.76$ when various concentrations of K.galanga is treated to them. At the highest concentration $(200 \mu \mathrm{g} / \mathrm{ml})$ the the extracts were found to be comparable to that of the common disinfectant ie $10 \%$ hypochlorite.

\section{MTT assay}

MTT assay was employed as the 
quantitative assessment tool for bacterial cell viability after treatment with extracts. A dose dependent increase in bacterial death which is comparable with standard disinfectant (sodium hypochlorite) was observed.

$200 \mu \mathrm{g}$ of sodium hypochlorite reduced the viability to $13 \%$ whereas the extracts reduced to approximately $24 \%$.

When fluorescent staining ie Ethidium bromide-Acridine orange was used to study the effect of the extracts on the cells, it was found that nearly $80 \%$ cells in biofilm showed compromised nuclear membrane integrity after treatment with extracts which was similar to that observed in sodium hypochlorite treatment.

\section{Determination of anti-plasmid activity}

When P.aeruginosa biofilms were treated with ,S.aromaticum extract and K.galanga extract to study the antiplasmid potential of the extracts,it was found that K.galanga has higher potential to cure plasmids than S.aromaticum.

Irrational usage of antibiotics has rendered many organisms resistant to a wide spectrum of antibiotics, a concern which draws serious attention. Pseudomonas aeruginosa, is a major opportunistic pathogen which is responsible for many chronic and acute infections. Apart from the intrinsic resistance, the ability of Pseudomonas spp to form biofilms makes it a difficult candidate for antibiotic therapy (Tsiry et al., 2015)

Table.1 Antimicrobial activity of S.aromaticum and K.galanga

\begin{tabular}{|c|c|c|c|c|}
\hline & \multicolumn{3}{|c|}{ Zone of inhibition (mm) } & \multirow{2}{*}{$\begin{array}{c}\text { Zone of inhibition } \\
(\mathrm{mm}) \text { by } \\
\text { streptomycin } \\
\end{array}$} \\
\hline & $25 \mu \mathrm{g} / \mathrm{ml}$ & $50 \mu \mathrm{g} / \mathrm{ml}$ & $100 \mu \mathrm{g} / \mathrm{ml}$ & \\
\hline S.aromaticum & $15+/-1$ & $20+/-2$ & $30+/-2$ & $29+/-3$ \\
\hline K.galanga & $12+/-0$ & $13+/-1$ & $16+/-2$ & $30+/-3$ \\
\hline
\end{tabular}

Table.2 Percentage viability of P.aeruginosa biofilms in the presence of extracts

\begin{tabular}{|c|c|c|c|}
\hline $\begin{array}{c}\text { Concentration } \\
\text { in } \mathbf{u g} / \mathbf{m l}\end{array}$ & $\begin{array}{c}\text { Sodium } \\
\text { hypochlorite }\end{array}$ & K.galanga & S. aromaticum \\
\hline 25 & $27.5 \pm 0.15$ & $38.05 \pm 0.05$ & $38.5 \pm 1.5$ \\
\hline 50 & $20.4 \pm 3.4$ & $36.2 \pm 1.2$ & $35.9 \pm 1.9$ \\
\hline 100 & $15.5 \pm 0.2$ & $29.3 \pm 3.3$ & $35.5 \pm 3.5$ \\
\hline 200 & $13.1 \pm 1$ & $24.3 \pm 1.3$ & $23.3 \pm 1.7$ \\
\hline
\end{tabular}


Fig.1 Antimicrobial activity of (a) S.aromaticum (b) K.galanga
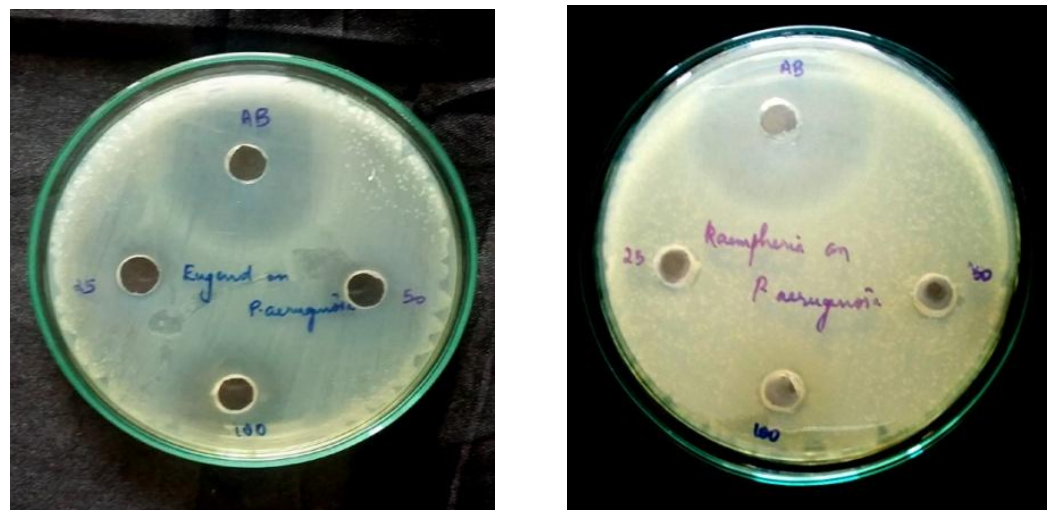

Fig.2 Ethidium Bromide-Acridine Orange staining of P.aeruginosa biofilms

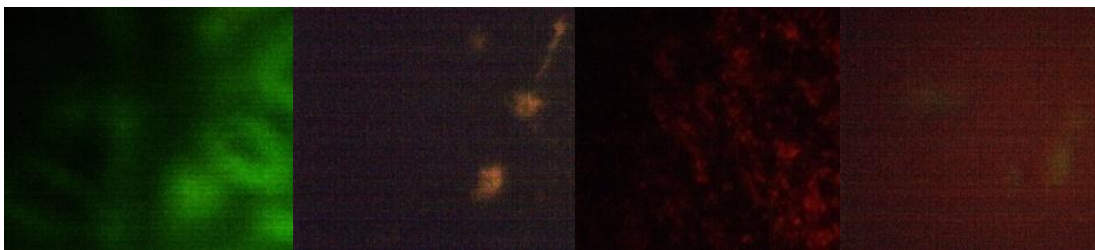

\section{Control \\ Hypochlorite \\ S.aromaticum \\ K.galanga}

Graph.1 Percentage viability of P.aeruginosa biofilms in the presence of extracts

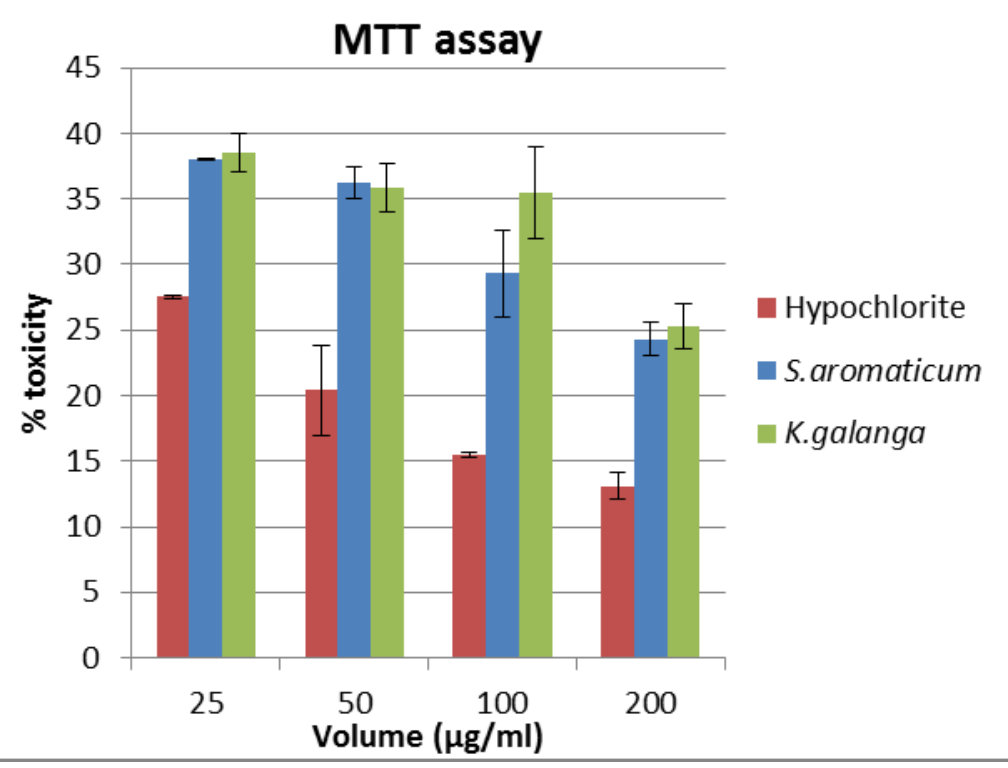

Administration of phytochemical based drugs can be a potent strategy for reducing antibiotic resistance and biofilm formation in micro organisms (Masak et al., 2014, Rudrappa and Bais 2008). In the present study we selected S.aromaticum and $K$. galanga owing to their potent antibacterial activities. $\quad 100 \mu \mathrm{g} / \mathrm{ml}$ of extracts was showing significant activity which was comparable to the standard antibiotics used. 
The extracts can be a potent alternative to overcome the adverse drug reactions, multiple drug resistance and biomagnifications issues exhibited by irrational antibiotic usage.

It is noteworthy that the extracts efficiently inhibited the formation of biofilm as determined by the modified methods of O'Toole, 2011, and the inhibition of biofilm formation was similar to that of sodium hypochlorite. $200 \mu \mathrm{g} / \mathrm{ml}$ of both extracts exhibited almost similar biofilm inhibition. Apart from that, performing MTT assay helped to understand the relation between the concentration of the extracts and the viability of Pseudomonas in biofilm Its results has shown significant decrease in bacterial cell viability in biofilm upon treatment with higher concentrations of extracts. Both MTT and fluorescent staining has shown concomitant decrease in live bacteria of biofilm.

\section{Fluorescent Staining of Pseudomonas biofilm}

Fluorescent staining exploits the differential staining ability of acridine orange and ethidium bromide to nucleus based on their membrane stability. Ethidium bromide permeates damaged or dead nuclei staining them orange whereas live cell shows mostly green (Bruno et al., 1996). The figures (Fig.2) clearly depicts increased cell death in $S$ aromactium treated cells followed by $K$ galanga.

Plasmid destabilization or plasmid curing is quite significant when focusing on the deleterious effects of plasmid borne drug resistance.The resistance towards drugs is contributed by the plasmids and hence it needed to find natural candidates that can actually overcome drug resistance developed by bacteria. Agarose gel electrophoresis (Fig
No:3) has shown relative decrease in plasmids of $S$ aromaticum and $K$ galanga treated extracts in comparison with sodium hypochlorite. Most of the efficient curing agents such as acridine orange, ethidium bromide or sodium dodecyl sulphate are toxic to mammals in one form or another which limits their therapeutic or industrial applications (Spengler et al., 2006). The plasmid curing potential of phytochemical is in accordance with the efficiency of heterocyclic compounds to bind differentially with different structures of DNA. The plasmid DNA that is supposed to be in its super helical state binds more that its linear or open circular form. Plasmid elimination is advantageous in this aspect since the compounds are not mutagenic and the anti plasmid activity entirely depends on energy of orbitals.

In conclusion, the study demonstrated the antimicrobial potential S.aromaticum and K.galanga with respect to its anti biofilm and anti plasmid activity against Pseudomonas spp. The results substantiates the utility of $S$. aromaticum as a potent combinatorial anti microbial agent against Pseudomonas spp.

\section{References}

Bruno,J.G., Sincock, S.A., Stopa, P.J. Highly selective acridine and ethidium staining of bacterial DNA and RNA. Biotech Histochem. 1996;Vol 1(3):130-6.

Cha,C., Gao, P., Chen,Y.C., Shaw, P.D and Farrand, S.K. Production of acylhomoserine lactone quorum-sensing signals by gram-negative plantassociated bacteria. Molec PlantMicrobe Interact .1998; Vol 11: 11191129.

Chirangini, P., Sinha, S. K. and Sharma,G.J. In vitro propagation and microrhizome induction in Kaempferia galanga Linn. 
and K.rotunda Linn. Indian J of Biotech. 2005; Vol 4:404-08.

Fu ,Y., Zu ,Y,. Chen, L., Shi, X., Wang ,Z., Sun, S.and Efferth, T. Antimicrobial activity of clove and rosemary essential oils alone and in combination. Phytother. Res .2007; Vol 21: 989-994.

Hengwei Wang, Hairong Cheng,Fengqing Wang, Dongzhi Wei,Xuedong Wang. An improved 3-(4,5-dimethylthiazol-2yl) 2, 5 diphenyl tetrazolium bromide (MTT) reduction assay for evaluating the viability of Escherichia coli cells. Journal of microbiological methods. 2010. Vol (82):330-333.

Horstkotte, D. K., Weist ,K., Ruden,H Better understanding of the pathogenesis of prosthetic valve endocarditis-recent perspectives for prevention strategies. $J$ Heart Valve Dis . 1998 ; Vol 7: 313-5.

Jia,P., Xue, Y.J., Duan, X.J., Shao, S.H. 2011. Effect of cinnamaldehyde on biofilm formation and sarA expression by methicillin resistant Staphylococcus aureus. Letters of Applied Microbiology. Vol 53:409-416.

Kai L, Rui B, Xueming Z. Plasmid curing in bacteria. Wei sheng wu xue tong bao. 2001; Vol(5):99-103.

Masak, Cejkova, A., Schreiberova,O., Rezanka,T. Pseudomonas biofilms: possibilities of their control. FEMS Microbiology and Ecology, 2014; Vol. 89: 1-14.

Neils, H., Thomas, B., Michael, G., Molin,S., Oana, C. Antibiotic resistance of bacterial biofilms. Int.Journ of Antimicro agents.2010; Vol 35(4):322332.
O'Toole, G. A. Microtiter Dish Biofilm Formation Assay. Journal of Visualized Experiments. 2011; Vol(47), 2437.

Ribble, D., Goldstein, N.B., Shellman, Y.G.A simple technique for quantify apoptosis in 96 well plates.BMC biotechnol. 2005; Vol 5 (12).

Rudrappa, T., Bais, H.P. Curcumin, a known phenolic from Curcuma longa, attenuates the virulence of Pseudomonas aeruginosa PAO1 in whole plant and animal pathogenicity models, Journal of Agricultural and Food Chemistry, 2008;Vol. 56: 19551962.

Sharma, G., Rao, S., Bansal, A., Dang,S., Gupta, S., Gabrani, R. Pseudomonas biofilm: Potential Therapeutic targets. Biologicals.2014.Vol 42(1):1-7.

Shyamala, M.P., Venukumar, M.R. and Latha, M.S. Antioxidant potential of Syzygium aromaticum (Gaertn.) Linn. (Cloves) in rats fed with high fat diet. Ind. J. Pharmacol. 2003; Vol 35: 99- 103.

Spengler,G., Molnár, A., Schelz, Z., Amaral, L., Sharples, D., Molnár J. The mechanism of plasmid curing in bacteria. Curr Drug Targets. 2006 Vol (7):823-41.

Strosmeyer, J., Maric, S. Characteristics and significance of microbial biofilm formation. Periodicum Biologorum. 2007; Vol 109

Tsiry, R., Quentin, L., Pierre, D.,El Jaziri, M. The Formation of Biofilms by Pseudomonas aeruginosa: A Review of the Natural and Synthetic Compounds Interfering with Control Mechanisms. BioMed Research International. 2015.

\section{How to cite this article:}

Neelima Christopher, Rajesh Ramachandran and Khaleel Ahamed Thaha. 2017. Anti Biofilm and Anti Plasmid Activites of Syzygium aromaticum and Kaempheria galanga against Pseudomonas aeruginosa.Int.J.Curr.Microbiol.App.Sci. 6(1): 859-865. doi: http://dx.doi.org/10.20546/ijcmas.2017.601.101 